\title{
Assessment of ligand extraction properties: an intercomparison campaign amongst EUROPARTners
}

\author{
By C. Hill ${ }^{1}$, , J.-F. Desreux ${ }^{2}$, C. Ekberg ${ }^{3}$, A. Glez Espartero ${ }^{4}$, M. Galetta ${ }^{5}$, G. Modolo ${ }^{6}$, A. Geist ${ }^{7}$, P. Selucky ${ }^{8}$, J. Narbutt ${ }^{9}$ \\ and C. Madic ${ }^{10}$ \\ ${ }^{1}$ CEA Marcoule (DEN/DRCP/SCPS/LCSE), bât. 399, BP 17171, 30207 Bagnols-sur-Cèze cedex, France \\ 2 University of Liège, Coordination and Radiochemistry, Sart Tilman B6, 4000 Belgium \\ 3 Chalmers University of Technology, Nuclear Chemistry Department of Materials and Surface Chemistry, 41296 Göteborg, Sweden \\ ${ }_{5}^{4}$ CIEMAT, Avda. Complutense 22, Edificio18, 28040 Madrid, Spain \\ ${ }_{6}^{5}$ POLIMI, Department of Nuclear Engineering, Via Ponzio 34/3, Milano, Italy \\ ${ }^{6}$ Forschungszentrum Jülich GmBH, FZJ, ISR-3, 52425 Jülich, Germany \\ ${ }^{7}$ Forschungszentrum Karlsruhe, Institut für Nukleare Entsorgung, Karlsruhe, Germany \\ ${ }^{8}$ Nuclear Research Institute REZ, 25068 Rez, Czech Republic \\ ${ }^{9}$ Institute of Nuclear Chemistry and Technology, ul. Dorodna 16, 03-195 Warszawa, Poland \\ ${ }^{10}$ CEA Saclay (DEN/DDIN), 91191 Gif-sur-Yvette, France
}

(Received May 21, 2007; accepted in revised form July 29, 2007)

\section{Liquid-liquid extraction / Ligand assessment / CMPO / TPTZ / BTP / Lanthanides / Actinides}

Summary. An intercomparison campaign was organized at the beginning of the European FP6 EUROPART Integrated Project, among the partners involved in the assessment of the extracting properties of novel ligands, in order to check their accuracy and reliability when determining metal cation distribution ratios. Three different extracting systems, presenting various selectivity and affinity towards trivalent actinides were selected: (i) CMPO, (ii) TPTZ and (iii) BTP. Although some differences could be pointed out in the implementation of liquid-liquid extraction tests, the distribution ratios measured by the nine partners were fairly reproducible $(<20 \%$ deviation) for the first two extracting systems. However, large discrepancies occurred when testing the third extracting system, due to its strong hydrolytic instability, thus pointing out the difficulty of assessing extraction properties of instable ligands.

\section{Introduction}

EUROPART [1], an Integrated Project from the 6th European Framework Program (2004-2007), was devoted to the development of hydrometallurgical and pyrometallurgical processes for the partitioning of actinides. Among the various Tasks related to hydrometallurgical processes (in Work Packages 1 to 4), Task 3 aimed at assessing the extracting properties of newly synthesized ligands, through series of liquid-liquid extraction tests performed in micro-tubes on surrogate aqueous feeds spiked with radiotracers. Thus, the results obtained in Task 3 (mainly distribution ratios) were crucial for the outcome of new ligands designed as potential candidates for process development.

\footnotetext{
*Author for correspondence (E-mail: clement.hill@ cea.fr).
}

Since several partners of the EUROPART consortium were involved in the screening activities (Task 3), it appeared sensed, and preferable for the sake of the project (mutual confidence between organic synthesizers and screeners), to organise an intercomparison campaign among extraction property assessors. The objective of this campaign was to check the partners' accuracy when determining metal cation distribution ratios and thus to challenge their reliability when assessing the extraction properties of novel ligands. Three different extracting systems, known for their ability to extract trivalent actinides more or less selectively were selected for this intercomparison campaign: (i) CMPO, (ii) TPTZ and (iii) BTP.

Herein are reported the results of this intercomparison campaign carried out in 2004 among 9 EUROPARTners (CEA, France, Chalmers Technological University, Sweden, CIEMAT, Spain, FZK-INE and FZJ, Germany, ICHTJ, Poland, NRI, Czech Republic, POLIMI, Italy, and University of Liège, Belgium), able to handle radioactive materials. It is the first ever reported international campaign comparing the ability to determine distribution ratios.

\section{Preparation of the intercomparison campaign}

The three extracting systems chosen for the intercomparison campaign are detailed hereafter:

1. Solvent No. 1, based on CMPO and TBP (Fig. 1), used in the well known TRUEX process [2] co-extracting trivalent lanthanides and actinides;

2. Solvent No.2, a trisynergistic mixture based on TPTZ (a nitrogen tridentate ligand), DMDBTDMA (a malonamide used as a modifier) and $\alpha$-cyano-capric acid (Fig. 2), which extracts trivalent actinides selectively through a proton exchange mechanism [3];

3. Solvent No. 3, a binary mixture consisting of iso-propylBTP (a nitrogen tridentate ligand) and DMDOHEMA 


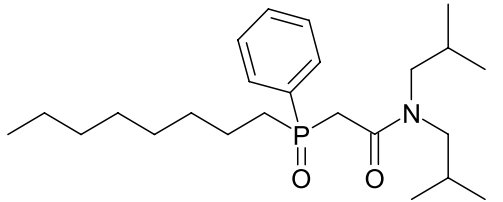

CMPO

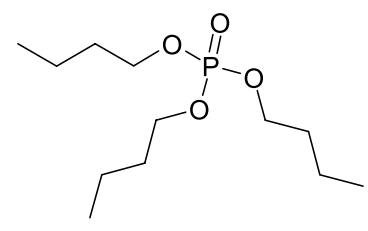

TBP

Fig. 1. Extraction system No. 1.

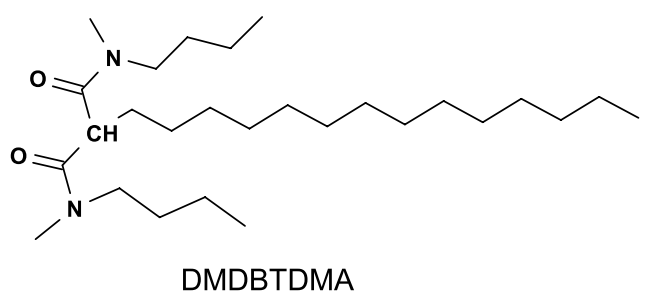<smiles>CCCCCCCCC(C#N)C(=O)O</smiles>

$\alpha$-Cyano-capric acid

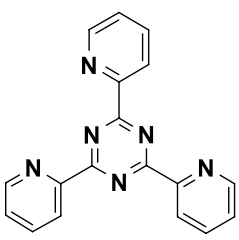

TPTZ

Fig. 2. Extraction system No. 2.

(a malonamide used as a phase transfer catalyst) (Fig. 3), which was developed as the SANEX solvent in PARTNEW [4] (previous FP5 Integrated Project) and is expected to show fairly high selectivity towards An(III).

The compositions of these three solvents were chosen as follows:

1. Solvent No. 1: $[\mathrm{CMPO}]=0.1 \mathrm{~mol} / \mathrm{L}+[\mathrm{TBP}]=1 \mathrm{~mol} / \mathrm{L}$ in TPH;

2. Solvent No. 2: $[$ TPTZ $]=0.1 \mathrm{~mol} / \mathrm{L}+[\mathrm{H} \alpha$-cyanocapric $]$ $=1 \mathrm{~mol} / \mathrm{L}+[\mathrm{DMDBTDMA}]=1 \mathrm{~mol} / \mathrm{L}$ in TPH ;

3. Solvent No. 3: $[i \mathrm{Pr}-\mathrm{BTP}]=0.01 \mathrm{~mol} / \mathrm{L}+$ $[\mathrm{DMDOHEMA}]=0.5 \mathrm{~mol} / \mathrm{L}$ in $n$-octanol.

CMPO was provided by Xymax Company (Boca Raton, Florida, US), $\alpha$-cyanocapric acid, DMDBTDMA and DMDOHEMA were synthesized by Pharmasynthèse Laboratory (Paris, France), TBP and TPTZ were purchased from Aldrich and TPH from Novasep Company (Pompey,<smiles>CC(C)c1nnc(-c2cccc(-c3nnc(C(C)C)c(C(C)C)n3)n2)nc1C(C)C</smiles>

i Pr-BTP

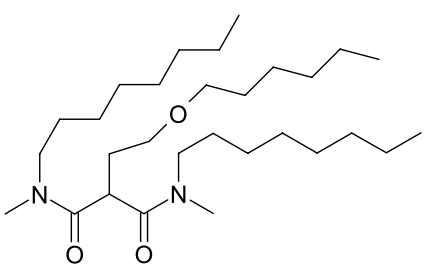

DMDOHEMA

Fig. 3. Extraction system No. 3 .

France), $i$ Pr-BTP was synthesized at CEA-Marcoule [5]. All these reagents were used without further purification.

$50 \mathrm{~mL}$ of each three solvents were prepared at CEAMarcoule and samples of approximately $5 \mathrm{~mL}$ were sent to the different EUROPARTners involved in the intercomparison campaign with some recommendations on the experimental conditions to follow when performing the extraction tests: the nitric acid concentrations proposed for the different aqueous feeds (spiked with ${ }^{152} \mathrm{Eu}$ (III) and ${ }^{241} \mathrm{Am}$ (III) to simulate the chemical behaviours of trivalent lanthanides and actinides respectively), were chosen according to the extraction efficiency of each of these three solvents:

1. $\left[\mathrm{HNO}_{3}\right]_{\text {ini }}=1$ and $2 \mathrm{~mol} / \mathrm{L}$ for solvent No. 1 ;

2. $\left[\mathrm{HNO}_{3}\right]_{\text {ini }}=0.1$ and $0.15 \mathrm{~mol} / \mathrm{L}$ for solvent No. 2;

3. $\left[\mathrm{HNO}_{3}\right]_{\text {ini }}=1 \mathrm{~mol} / \mathrm{L}$ for solvent No. 3 .

It was recommended to pre-equilibrate solvents No. 1 and No. 3 with nitric acid solutions of the same concentration as the corresponding spiked feeds, using a phase volume ratio of $3\left(V_{\mathrm{aq}} / V_{\text {org }}\right)$. It was also recommended to perform the liquid-liquid extraction experiments with a phase volume ratio of 1 and to mix the two phases in contact for at least $60 \mathrm{~min}$ (to insure equilibrium state) at $25^{\circ} \mathrm{C}$ (if monitoring the temperature while mixing was possible). Though, no indication was given to the partners about potential instability of the tested solvents $v s$. acidic hydrolysis.

\section{Results and discussions}

Amongst the 9 EUROPARTners involved in this campaign, some differences could be pointed out as regard the experimental setups used to carry out the liquid-liquid extraction tests, as well as the procedures followed when preequilibrating the solvents with nitric acid or when performing the extraction tests. These differences mainly concerned:

- The materials of the micro-tubes: glass or plastic;

- The volumes of the aqueous and organic phases;

- The shaking mode of the micro-tubes: automatic vortex device or hand shaking; 


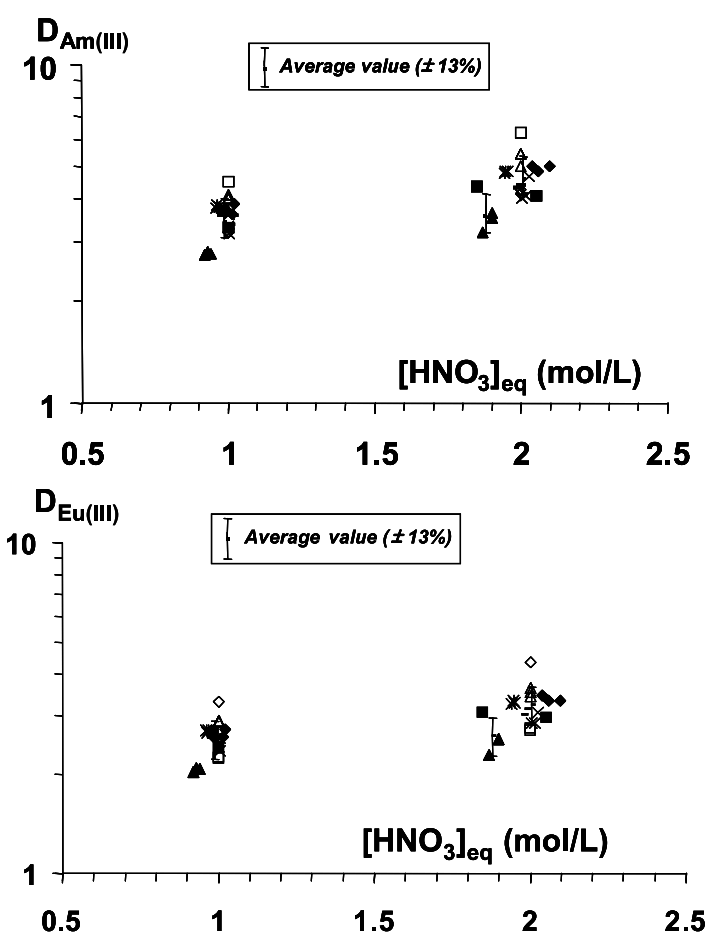

Organic solutions: $[\mathrm{CMPO}]_{\mathrm{ini}}=0.1 \mathrm{~mol} / \mathrm{L}+[\mathrm{TBP}]_{\mathrm{ini}}=1$ $\mathrm{mol} / \mathrm{L}$ in $\mathrm{TPH} .22^{\circ} \mathrm{C}<\mathrm{T}<25^{\circ} \mathrm{C}$.

Aqueous solutions: ${ }^{152} \mathrm{Eu}(\mathrm{III})$ and ${ }^{241} \mathrm{Am}(\mathrm{III})$ at trace level in $\mathrm{HNO}_{3}$.

Fig. 4. Results of the intercomparative campaign on solvent No. 1 (CMPO/TBP).

Table 1. Mean values observed for solvent No. 1 (CMPO/TBP).

\begin{tabular}{lccc}
\hline $\begin{array}{l}{\left[\mathrm{HNO}_{3}\right]_{\text {mean }}} \\
(\mathrm{mol} / \mathrm{L})\end{array}$ & $D_{\mathrm{Eu}}$ & $D_{\mathrm{Am}}$ & $\mathrm{SF}_{\mathrm{Am} / \mathrm{Eu}}$ \\
\hline 0.99 & $2.55 \pm 0.31$ & $3.54 \pm 0.46$ & $1.39 \pm 0.03$ \\
1.88 & $2.61 \pm 0.33$ & $3.67 \pm 0.49$ & $1.41 \pm 0.03$ \\
2.01 & $3.24 \pm 0.39$ & $4.74 \pm 0.58$ & $1.46 \pm 0.05$ \\
\hline
\end{tabular}

(see Fig. 4 for experimental conditions)

- The spectrometers employed to determine the gamma radioactivity of the samples;

- The mixing time and the number of contacts when preequilibrating the solvents;

- The ageing of the pre-equilibrated solvents before performing the tests;

- The temperature monitoring during the tests;

- The number of test replicates.

Not all the partners measured the initial activity of the feeds, to check the mass balances of the tracers after extraction. Not all the partners were able (or took care) to measure the acidity of the aqueous solutions initially (after spiking with ${ }^{152} \mathrm{Eu}(\mathrm{III})$ and ${ }^{241} \mathrm{Am}(\mathrm{III})$ ) or after their contacts with the organic solvents. In the latter cases, the acidities were assumed to be those expected for the feeds, prior to extraction.

The aim of the intercomparison campaign being to check each partner's accuracy when determining a metal cation distribution ratio and not to rank its skills among a team of ligand assessors, the results will refer to numbers (ran-
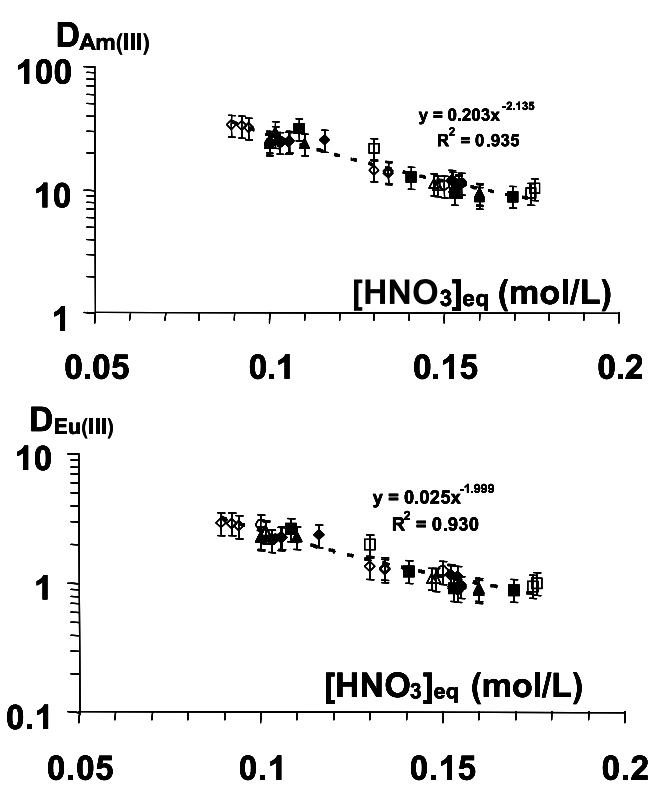

Org. solutions: $[\mathrm{TPTZ}]_{\mathrm{ini}}=0.1 \mathrm{~mol} / \mathrm{L}+$ $[\mathrm{H} \alpha \text {-cyanocapric }]_{\text {ini }}=1 \mathrm{~mol} / \mathrm{L}+[\text { DMDBTDMA }]_{\text {ini }}=1 \mathrm{~mol} / \mathrm{L}$ in TPH.

Aqueous solutions: ${ }^{152} \mathrm{Eu}(\mathrm{III})$ and ${ }^{241} \mathrm{Am}$ (III) at trace level in $\mathrm{HNO}_{3} .22^{\circ} \mathrm{C}<\mathrm{T}<25^{\circ} \mathrm{C}$.

Fig. 5. Results of the intercomparative campaign on solvent No. 2 (TPTZ/DMDBTDMA/CNCOOH).

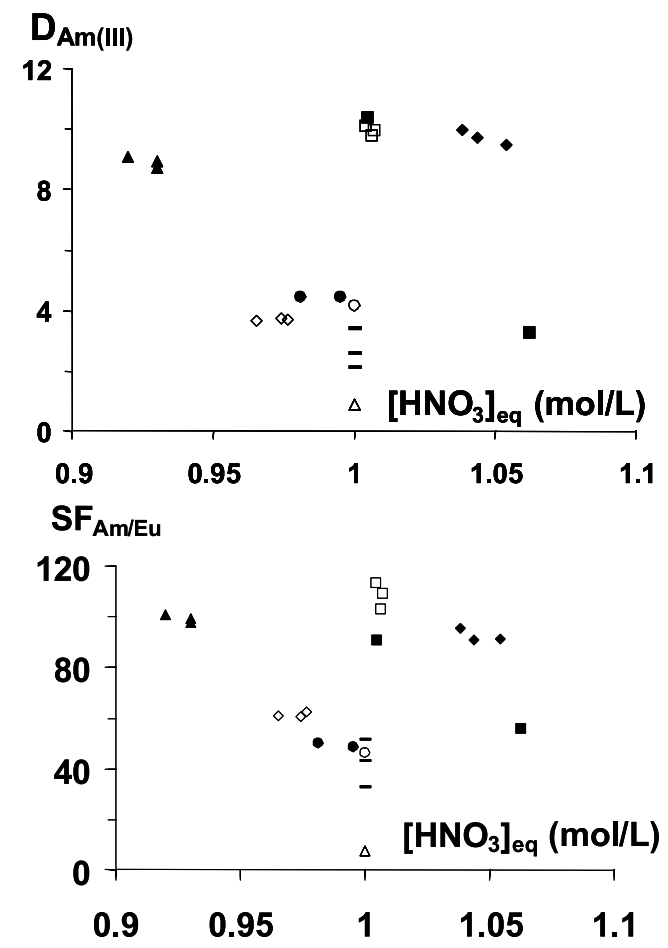

Organic solutions: $[i \mathrm{Pr}-\mathrm{BTP}]_{\mathrm{ini}}=0.01 \mathrm{~mol} / \mathrm{L}+$

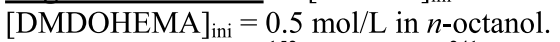

Aqueous solutions: ${ }^{152} \mathrm{Eu}(\mathrm{III})$ and ${ }^{241} \mathrm{Am}(\mathrm{III})$ at trace level in $\mathrm{HNO}_{3} .22^{\circ} \mathrm{C}<\mathrm{T}<25^{\circ} \mathrm{C}$.

Fig. 6. Results of the intercomparative campaign on solvent No. 3 ( $i \mathrm{Pr}$ BTP/DMDOHEMA).

domly selected for each three extraction systems), so that the partners' identities will remain anonymous. Hereafter are discussed the results of this campaign, system by system. 


\section{Solvent No. 1: the "CMPO/TBP” mixture}

Fig. 4 displays the extraction data measured experimentally by the nine EUROPARTners, involved in the intercomparison campaign, with the "CMPO/TBP" mixture. This extraction system is well known for its affinity for trivalent $4 f$ and $5 f$ elements. However, it is also well known that its extraction efficiency directly depends on the concentration of nitrate anions, and thus that of nitric acid, at equilibrium [6]. Table 2 (see experimental annex) shows that the acidities of the aqueous solutions differed from one partner to the other. It was therefore not possible to compare the experimental data altogether, and only those corresponding to similar values of $\left[\mathrm{HNO}_{3}\right]_{\mathrm{eq}}$ were used for intercomparison. Three average values were considered for $\left[\mathrm{HNO}_{3}\right]_{\text {eq }}: 1,1.9$ and $2 \mathrm{~mol} / \mathrm{L}$.
As shown in Table 1, around 13\% deviation and less than $4 \%$ deviation were respectively observed for the distribution ratios of ${ }^{152} \mathrm{Eu}(\mathrm{III})$ and ${ }^{241} \mathrm{Am}(\mathrm{III})$, and for the separation factors $\left(\mathrm{SF}_{\mathrm{Am} / \mathrm{Eu}}\right)$. Taking into account the differences encountered when implementing the liquid-liquid extraction tests in micro-tubes by the nine EUROPARTners, the discrepancies observed among experimental data are relatively small for this system, and prove the partners' reliability when determining distribution ratios.

\section{Solvent No. 2: the "TPTZ/DMDBTDMA/ CNCOOH" mixture}

The second system studied is known for the dependency of its extraction efficiency on the acidity of the aqueous phase, because of the proton exchange mechanism involved

Table 2. Results of the intercomparative campaign on solvent No. 1 (CMPO/TBP). Organic solutions: $[\mathrm{CMPO}]_{\text {ini }}=0.1 \mathrm{~mol} / \mathrm{L}+[\mathrm{TBP}]_{\text {ini }}=1 \mathrm{~mol} / \mathrm{L}$ in TPH. Aqueous solutions: ${ }^{152} \mathrm{Eu}(\mathrm{III})$ and ${ }^{241} \mathrm{Am}(\mathrm{III})$ at trace level in $\mathrm{HNO}_{3}$.

\begin{tabular}{|c|c|c|c|c|c|c|c|c|c|c|c|c|}
\hline Partner No. & \multicolumn{5}{|c|}{1} & \multicolumn{7}{|c|}{2} \\
\hline Preequilib. & \multicolumn{2}{|c|}{ No } & \multicolumn{3}{|c|}{ Yes } & \multicolumn{7}{|c|}{ Yes } \\
\hline $\begin{array}{l}V_{\text {org }}=V_{\text {aq }} \\
\text { Temperature }\end{array}$ & \multicolumn{5}{|c|}{$\begin{array}{c}700 \mu \mathrm{L} \\
25 \pm 0.5^{\circ} \mathrm{C}\end{array}$} & \multicolumn{7}{|c|}{$\begin{array}{l}500 \mu \mathrm{L} \\
25^{\circ} \mathrm{C}\end{array}$} \\
\hline$\left[\mathrm{HNO}_{3}\right]_{\mathrm{ini}}(\mathrm{M})$ & 1.23 & 2.28 & & .05 & 2.03 & & 1.03 & & & & 2.04 & \\
\hline $\begin{array}{l}{\left[\mathrm{HNO}_{3}\right]_{\mathrm{eq}}(\mathrm{M})} \\
D_{\mathrm{Eu}} \\
D_{\mathrm{Am}} \\
\mathrm{SF}_{\mathrm{Am} / \mathrm{Eu}}\end{array}$ & $\begin{array}{l}0.98 \\
2.6 \\
3.7 \\
1.4\end{array}$ & $\begin{array}{l}1.85 \\
3.1 \\
4.3 \\
1.4\end{array}$ & & $\begin{array}{l}.00 \\
.4 \\
.3\end{array}$ & $\begin{array}{l}2.05 \\
2.9 \\
4.1 \\
1.4\end{array}$ & $\begin{array}{l}1.01 \\
2.6 \\
3.6 \\
1.4\end{array}$ & $\begin{array}{l}0.99 \\
2.6 \\
3.7 \\
1.4\end{array}$ & $\begin{array}{l}1.02 \\
2.7 \\
3.9 \\
1.4\end{array}$ & & $\begin{array}{l}2.04 \\
3.4 \\
5.0 \\
1.4\end{array}$ & $\begin{array}{l}2.06 \\
3.3 \\
4.8 \\
1.5\end{array}$ & $\begin{array}{l}2.10 \\
3.3 \\
5.0 \\
1.5\end{array}$ \\
\hline Partner No. & \multicolumn{5}{|c|}{3} & \multicolumn{7}{|c|}{4} \\
\hline Preequilib. & \multicolumn{5}{|c|}{ Yes } & \multicolumn{7}{|c|}{ Yes } \\
\hline $\begin{array}{l}V_{\text {org }}=V_{\text {aq }} \\
\text { Temperature }\end{array}$ & \multicolumn{5}{|c|}{$\begin{array}{c}1000 \mu \mathrm{L} \\
25^{\circ} \mathrm{C}\end{array}$} & \multicolumn{7}{|c|}{$\begin{array}{c}800 \mu \mathrm{L} \\
23^{\circ} \mathrm{C}\end{array}$} \\
\hline$\left[\mathrm{HNO}_{3}\right]_{\mathrm{ini}}(\mathrm{M})$ & \multicolumn{3}{|c|}{1.015} & \multicolumn{2}{|c|}{2.00} & & 0.96 & & & \multicolumn{2}{|l|}{1.94} \\
\hline $\begin{array}{l}{\left[\mathrm{HNO}_{3}\right]_{\mathrm{eq}}(\mathrm{M})} \\
D_{\mathrm{Eu}} \\
D_{\mathrm{Am}} \\
\mathrm{SF}_{\mathrm{Am} / \mathrm{Eu}}\end{array}$ & $\begin{array}{l}1.00 \\
2.5 \\
3.4 \\
1.3\end{array}$ & $\begin{array}{l}1.01 \\
2.6 \\
3.6 \\
1.4\end{array}$ & & $\begin{array}{l}.98 \\
.0 \\
.3 \\
.4\end{array}$ & $\begin{array}{l}1.99 \\
3.1 \\
4.4 \\
1.4\end{array}$ & $\begin{array}{l}0.93 \\
2.1 \\
2.8 \\
1.3\end{array}$ & $\begin{array}{l}0.94 \\
2.1 \\
2.8 \\
1.3\end{array}$ & $\begin{array}{l}0.92 \\
2.0 \\
2.7 \\
1.3\end{array}$ & & $\begin{array}{l}1.87 \\
2.3 \\
3.2 \\
1.4\end{array}$ & $\begin{array}{l}1.90 \\
2.6 \\
3.5 \\
1.4\end{array}$ & $\begin{array}{l}1.90 \\
2.5 \\
3.6 \\
1.4\end{array}$ \\
\hline Partner No. & \multicolumn{5}{|c|}{5} & & \multicolumn{6}{|c|}{6} \\
\hline Preequilib. & \multicolumn{5}{|c|}{ Yes } & & \multicolumn{6}{|c|}{ Yes } \\
\hline $\begin{array}{l}V_{\text {org }}=V_{\text {aq }} \\
\text { Temperature }\end{array}$ & \multicolumn{5}{|c|}{$\begin{array}{c}500 \mu \mathrm{L} \\
22^{\circ} \mathrm{C}\end{array}$} & & \multicolumn{6}{|c|}{$\begin{array}{c}500 \mu \mathrm{L} \\
22^{\circ} \mathrm{C}\end{array}$} \\
\hline$\left[\mathrm{HNO}_{3}\right]_{\mathrm{ini}}(\mathrm{M})$ & & 1.01 & & & 2.07 & & & $?$ & & & $?$ & \\
\hline $\begin{array}{l}{\left[\mathrm{HNO}_{3}\right]_{\text {eq }}(\mathrm{M})} \\
D_{\mathrm{Eu}} \\
D_{\mathrm{Am}} \\
\mathrm{SF}_{\mathrm{Am} / \mathrm{Eu}}\end{array}$ & $\begin{array}{l}1.01 \\
2.3 \\
3.2 \\
1.3\end{array}$ & $\begin{array}{l}1.00 \\
2.4 \\
3.3 \\
1.4\end{array}$ & $\begin{array}{l}1.00 \\
2.6 \\
3.6 \\
1.4\end{array}$ & $\begin{array}{l}2.02 \\
2.9 \\
4.1 \\
1.4\end{array}$ & $\begin{array}{l}2.00 \\
2.9 \\
4.0 \\
1.4\end{array}$ & $\begin{array}{l}2.03 \\
3.1 \\
4.7 \\
1.5\end{array}$ & $\begin{array}{l}0.96 \\
2.7 \\
3.8 \\
1.4\end{array}$ & $\begin{array}{l}0.96 \\
2.7 \\
3.8 \\
1.4\end{array}$ & $\begin{array}{l}0.97 \\
2.7 \\
3.8 \\
1.4\end{array}$ & $\begin{array}{l}1.95 \\
3.3 \\
4.8 \\
1.5\end{array}$ & $\begin{array}{l}1.95 \\
3.3 \\
4.8 \\
1.5\end{array}$ & $\begin{array}{l}1.94 \\
3.3 \\
4.8 \\
1.5\end{array}$ \\
\hline Partner No. & \multicolumn{2}{|c|}{7} & \multicolumn{4}{|c|}{8} & \multicolumn{6}{|c|}{9} \\
\hline Preequilib. & \multicolumn{2}{|c|}{ Yes } & \multicolumn{4}{|c|}{ Yes } & \multicolumn{6}{|c|}{$?$} \\
\hline $\begin{array}{l}V_{\text {org }}=V_{\text {aq }} \\
\text { Temperature }\end{array}$ & \multicolumn{2}{|c|}{$\begin{array}{c}500 \mu \mathrm{L} \\
?\end{array}$} & \multicolumn{4}{|c|}{$\begin{array}{c}1500 \mu \mathrm{L} \\
25^{\circ} \mathrm{C}\end{array}$} & \multicolumn{6}{|c|}{$\begin{array}{l}500 \mu \mathrm{L} \\
25^{\circ} \mathrm{C}\end{array}$} \\
\hline $\begin{array}{l}{\left[\mathrm{HNO}_{3}\right]_{\text {ini }}(\mathrm{M})} \\
{\left[\mathrm{HNO}_{3}\right]_{\text {eq }}(\mathrm{M})}\end{array}$ & $\stackrel{?}{1^{a}}$ & $\stackrel{?}{2^{a}}$ & \multicolumn{2}{|c|}{$\begin{array}{l}1.00 \\
1^{a}\end{array}$} & & & & $\stackrel{?}{1^{a}}$ & & & $\stackrel{?}{2^{a}}$ & \\
\hline $\begin{array}{l}D_{\mathrm{Eu}} \\
D_{\mathrm{Am}} \\
\mathrm{SF}_{\mathrm{Am} / \mathrm{Eu}}\end{array}$ & $\begin{array}{l}3.3 \\
4.5 \\
1.4\end{array}$ & $\begin{array}{l}4.4 \\
6.3 \\
1.4\end{array}$ & $\begin{array}{l}2.2 \\
3.2 \\
1.4\end{array}$ & $\begin{array}{l}2.2 \\
3.2 \\
1.4\end{array}$ & $\begin{array}{l}2.7 \\
4.1 \\
1.5\end{array}$ & $\begin{array}{l}2.7 \\
4.3 \\
1.6\end{array}$ & $\begin{array}{l}2.9 \\
4.0 \\
1.4\end{array}$ & $\begin{array}{l}2.9 \\
4.0 \\
1.4\end{array}$ & $\begin{array}{l}2.9 \\
4.1 \\
1.4\end{array}$ & $\begin{array}{l}3.4 \\
5.4 \\
1.6\end{array}$ & $\begin{array}{l}3.5 \\
5.0 \\
1.4\end{array}$ & $\begin{array}{l}3.6 \\
5.4 \\
1.5\end{array}$ \\
\hline
\end{tabular}

a: concentration assumed. 
Table 3. Results of the intercomparative campaign on solvent No. 2 (TPTZ/DMDBTDMA/CNCOOH). Org. solutions: $[\text { TPTZ }]_{\text {ini }}=0.1 \mathrm{~mol} / \mathrm{L}+[\mathrm{H} \alpha \text {-cyanocapric }]_{\text {ini }}=1 \mathrm{~mol} / \mathrm{L}+[\text { DMDBTDMA }]_{\text {ini }}=1 \mathrm{~mol} / \mathrm{L}$ in TPH. Aqueous solutions: ${ }^{152} \mathrm{Eu}(\mathrm{III})$ and ${ }^{241} \mathrm{Am}(\mathrm{III})$ at trace level in $\mathrm{HNO}_{3}$.

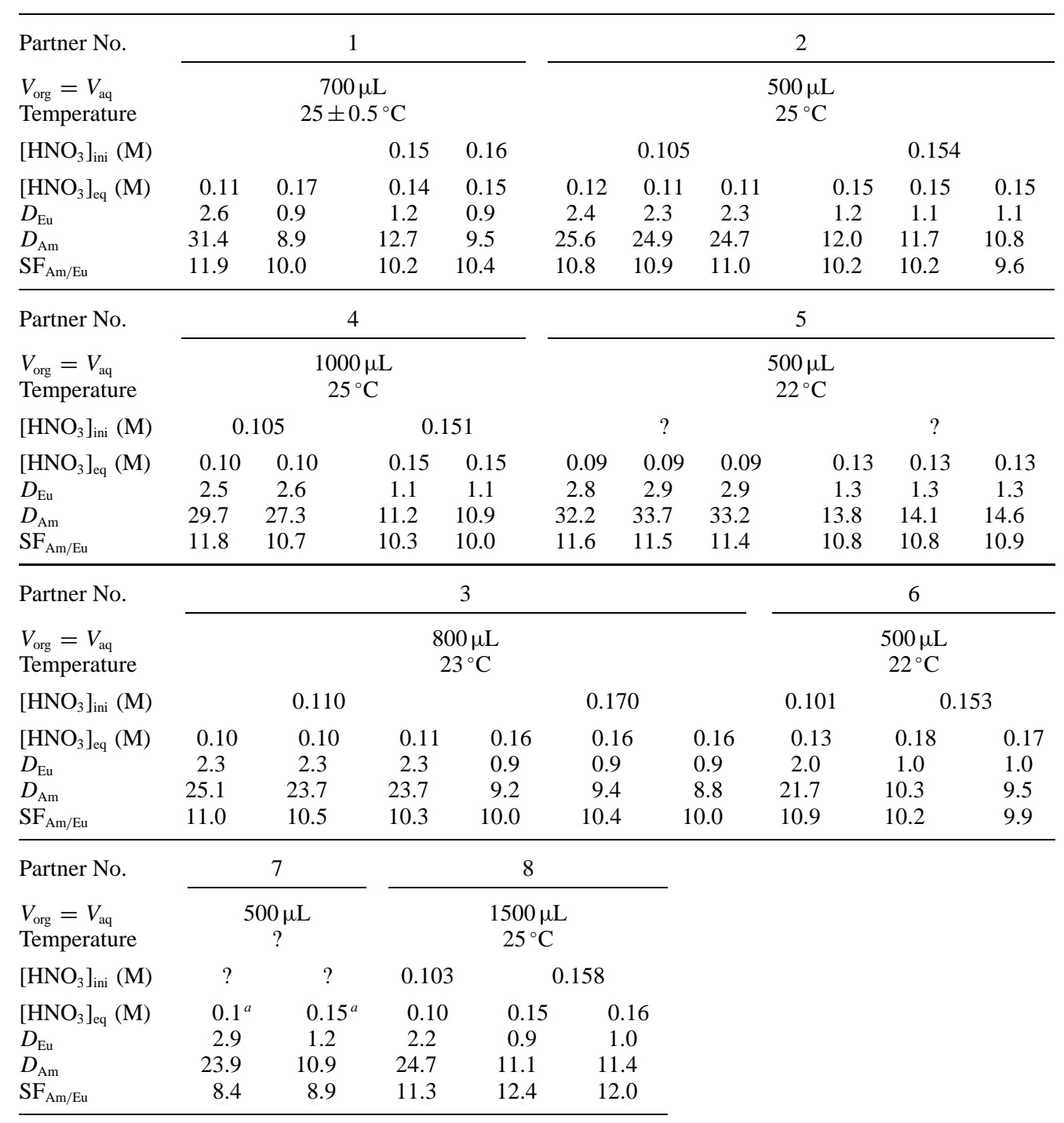

a: concentration assumed.

in the extraction of trivalent $4 f$ and $5 f$ elements. The latter metal cations usually require the exchange of three protons, while being extracted by lipophilic carboxylic acids, such as $\alpha$-cyanocapric acid.

Though, the presence in the extracting mixture of the malonamide DMDBTDMA, which can act as a solvating agent, especially at higher nitrate (nitric acid) concentrations, might favour the formation of mixed " $\alpha$-cyanocaprate/nitrate" complexes, therefore reducing the number of protons exchanged and thus the steepness of the slope observed, as suggested on Fig. 5: only two protons seem to be exchanged during the extraction of trivalent $4 f$ and $5 f$ elements by this ternary synergistic mixture. Thus, one nitrate anion might also be involved.

Based on the results collected in Table 3 (see experimental annex), an approx. 20\% deviation was observed among the $D_{\mathrm{Am}}$ and $D_{\mathrm{Eu}}$ values. This deviation is higher than the one observed for the first extracting system, but remains fairly appreciable, taking into account the differences in liquid-liquid extraction test implementation among the eight partners.
The selectivity of TPTZ based systems towards trivalent $5 f$ elements is expected to average 10: the mean $\mathrm{SF}_{\mathrm{Am} / \mathrm{Eu}}$ value observed in this campaign is 10.6 , with an $8 \%$ deviation. These figures prove the reliability of the data determined experimentally by the EUROPARTners involved in this intercomparison campaign.

\section{Solvent No. 3: the "iPr-BTP/DMDOHEMA" mixture}

Solvent No. 3 is based on a bis-triazine-pyridine well known for its high selectivity towards Am(III), usually exceeding $100\left(\mathrm{SF}_{\mathrm{Am} / \mathrm{Eu}}\right)$. However, this nitrogen heterocyclic ligand is also known for its weak stability vs. acidic hydrolysis, which can severely ruin its extraction efficiency and selectivity within a few hours.

In almost all cases reported in Table 4 (see experimental annex), the solvent samples have been pre-equilibrated (several times) with molar nitric acid prior to the extraction of the radiotracers. However, no recommendations had been given to the EUROPARTners as regard solvent protection against acidic hydrolysis. Thus, some solvent samples 
Table 4. Results of the intercomparative campaign on solvent No.3 (iPr-BTP/DMDOHEMA). Organic solutions: $[i \operatorname{Pr}-\mathrm{BTP}]_{\mathrm{ini}}=0.01 \mathrm{~mol} / \mathrm{L}+$ $[\text { DMDOHEMA }]_{\text {ini }}=0.5 \mathrm{~mol} / \mathrm{L}$ in $n$-octanol. Aqueous solutions: ${ }^{152} \mathrm{Eu}(\mathrm{III})$ and ${ }^{241} \mathrm{Am}(\mathrm{III})$ at trace level in $\mathrm{HNO}_{3}$.

\begin{tabular}{|c|c|c|c|c|c|c|c|c|c|}
\hline Partner No. & \multicolumn{3}{|c|}{1} & \multicolumn{3}{|c|}{2} & \multicolumn{3}{|c|}{3} \\
\hline $\begin{array}{l}\text { Preequilib. } \\
V_{\text {org }}=V_{\text {aq }} \\
\text { Temperature }\end{array}$ & \multicolumn{3}{|c|}{$\begin{array}{c}\text { Yes } \\
700 \mu \mathrm{L} \\
25 \pm 0.5^{\circ} \mathrm{C}\end{array}$} & \multicolumn{3}{|c|}{$\begin{array}{c}\text { Yes } \\
500 \mu \mathrm{L} \\
25^{\circ} \mathrm{C}\end{array}$} & \multicolumn{3}{|c|}{$\begin{array}{c}\text { Yes } \\
800 \mu \mathrm{L} \\
23^{\circ} \mathrm{C}\end{array}$} \\
\hline$\left[\mathrm{HNO}_{3}\right]_{\text {ini }}(\mathrm{M})$ & \multicolumn{3}{|c|}{1.05} & \multicolumn{3}{|c|}{1.03} & \multicolumn{3}{|c|}{0.96} \\
\hline $\begin{array}{l}{\left[\mathrm{HNO}_{3}\right]_{\mathrm{eq}}(\mathrm{M})} \\
D_{\mathrm{Eu}} \\
D_{\mathrm{Am}} \\
\mathrm{SF}_{\mathrm{Am} / \mathrm{Eu}}\end{array}$ & & $\begin{array}{l}1.00 \\
1.1 \times 10^{-1} \\
10.4 \\
91\end{array}$ & & $\begin{array}{l}1.04 \\
1.0 \times 10^{-1} \\
10.0 \\
95\end{array}$ & $\begin{array}{c}1.05 \\
1.0 \times 10^{-1} \\
9.5 \\
91\end{array}$ & $\begin{array}{c}1.04 \\
1.1 \times 10^{-1} \\
9.7 \\
91\end{array}$ & $\begin{array}{c}0.92 \\
9.0 \times 10^{-2} \\
9.1 \\
101\end{array}$ & $\begin{array}{c}0.93 \\
8.9 \times 10^{-2} \\
8.7 \\
98\end{array}$ & $\begin{array}{c}0.93 \\
9.0 \times 10^{-2} \\
9.0 \\
99\end{array}$ \\
\hline Partner No. & \multicolumn{3}{|c|}{4} & \multicolumn{3}{|c|}{5} & \multicolumn{3}{|c|}{6} \\
\hline $\begin{array}{l}\text { Preequilib. } \\
V_{\text {org }}=V_{\text {aq }} \\
\text { Temperature }\end{array}$ & \multicolumn{3}{|c|}{$\begin{array}{c}\text { Yes } \\
500 \mu \mathrm{L} \\
23^{\circ} \mathrm{C}\end{array}$} & \multicolumn{3}{|c|}{$\begin{array}{c}\text { Yes } \\
500 \mu \mathrm{L} \\
22^{\circ} \mathrm{C}\end{array}$} & \multicolumn{3}{|c|}{$\begin{array}{c}\text { Yes } \\
1000 \mu \mathrm{L} \\
25^{\circ} \mathrm{C}\end{array}$} \\
\hline$\left[\mathrm{HNO}_{3}\right]_{\text {ini }}(\mathrm{M})$ & \multicolumn{3}{|c|}{1.01} & \multicolumn{3}{|c|}{$?$} & \multicolumn{3}{|c|}{1.02} \\
\hline $\begin{array}{l}{\left[\mathrm{HNO}_{3}\right]_{\mathrm{eq}}(\mathrm{M})} \\
D_{\mathrm{Eu}} \\
D_{\mathrm{Am}} \\
\mathrm{SF}_{\mathrm{Am} / \mathrm{Eu}} \\
\end{array}$ & $\begin{array}{c}1.01 \\
9.1 \times 10^{-2} \\
10.0 \\
109 \\
\end{array}$ & $\begin{array}{c}1.00 \\
8.9 \times 10^{-2} \\
10.1 \\
113 \\
\end{array}$ & $\begin{array}{c}1.01 \\
9.5 \times 10^{-2} \\
9.8 \\
103 \\
\end{array}$ & $\begin{array}{c}0.97 \\
6.0 \times 10^{-2} \\
3.7 \\
61 \\
\end{array}$ & $\begin{array}{c}0.97 \\
6.2 \times 10^{-2} \\
3.8 \\
61 \\
\end{array}$ & $\begin{array}{c}0.98 \\
6.0 \times 10^{-2} \\
3.7 \\
62 \\
\end{array}$ & $\begin{array}{c}1.00 \\
1.1 \times 10^{-} \\
0.8 \\
7 \\
\end{array}$ & )$^{-1}$ & $\begin{array}{l}1.00 \\
\times 10^{-1} \\
.8 \\
7\end{array}$ \\
\hline Partner No. & \multicolumn{3}{|c|}{7} & \multicolumn{3}{|c|}{8} & \multicolumn{3}{|c|}{9} \\
\hline $\begin{array}{l}\text { Preequilib. } \\
V_{\text {org }}=V_{\text {aq }} \\
\text { Temperature }\end{array}$ & \multicolumn{3}{|c|}{$\begin{array}{c}\text { Yes } \\
500 \mu \mathrm{L} \\
?\end{array}$} & \multicolumn{3}{|c|}{$\begin{array}{c}\text { Yes } \\
1500 \mu \mathrm{L} \\
25^{\circ} \mathrm{C}\end{array}$} & \multicolumn{3}{|c|}{$\begin{array}{c}? \\
500 \mu \mathrm{L} \\
25^{\circ} \mathrm{C}\end{array}$} \\
\hline$\left[\mathrm{HNO}_{3}\right]_{\text {ini }}(\mathrm{M})$ & & & & \multicolumn{3}{|c|}{1} & \multicolumn{3}{|c|}{1.00} \\
\hline $\begin{array}{l}{\left[\mathrm{HNO}_{3}\right]_{\mathrm{eq}}(\mathrm{M})} \\
D_{\mathrm{Eu}} \\
D_{\mathrm{Am}} \\
\mathrm{SF}_{\mathrm{Am} / \mathrm{Eu}}\end{array}$ & & $\begin{array}{c}1^{a} \\
9.0 \times 10^{-2} \\
4.2 \\
46\end{array}$ & & $\begin{array}{c}0.98 \\
8.9 \times 10^{-2} \\
4.4 \\
50\end{array}$ & 2 & $\begin{array}{l}1.00 \\
.1 \times 10^{-2} \\
4.4 \\
49\end{array}$ & $\begin{array}{c}1.00 \\
6.5 \times 10^{-2} \\
2.1 \\
33\end{array}$ & $\begin{array}{c}1.00 \\
6.6 \times 10^{-2} \\
3.4 \\
52\end{array}$ & $\begin{array}{c}1.00 \\
6.0 \times 10^{-2} \\
2.6 \\
43\end{array}$ \\
\hline
\end{tabular}

a: concentration assumed.

have inevitably been hydrolysed during the too long preequilibration times or during their resting, between their acid pre-equilibration and the extraction of the radiotracers. This explains the large discrepancies observed on Fig. 6 for $D_{\mathrm{Am}}$ and $\mathrm{SF}_{\mathrm{Am} / \mathrm{Eu}}$, which should reach the values of 10 and 100 , respectively.

The intercomparison of the experimental results referring to solvent No. 3 shows that the EUROPARTners' reproducibility when determining distribution ratios strongly depends on the protocol followed when assessing the extraction properties of instable ligands. It points out the difficulties of handling novel ligands of unknown stability $v s$. hydrolysis, which might degrade before having been properly assessed.

\section{Conclusion}

Although different experimental protocols were followed by the nine EUROPARTners, different setups and materials were employed for the liquid-liquid extraction tests in micro-tubes, fairly good reproducibility was observed for the distribution ratios of ${ }^{152} \mathrm{Eu}(\mathrm{III})$ and ${ }^{241} \mathrm{Am}$ (III) $(<20 \%$ deviation), when implementing the CMPO and TPTZ based extracting systems. However, large discrepancies occurred when testing the BTP based extracting system, due to its strong hydrolytic instability, thus pointing out the difficulty of assessing extraction properties of instable ligands.
This international intercomparison campaign was the first of a kind in Europe and eased the comparison of all the extraction data acquired in the different laboratories all through the project.

Acknowledgment. We thank the Nuclear Fission Safety Program of the European Union under the EUROPART contract (FI6W-CT-2003508854).

\section{References}

1. Madic, C., Testard, F., Hanson, B., Ekberg, C., Pina, G., John, J., Arnaud, F., Walle, E., De Angelis, G., Modolo, G., Teixidor, F., Gruner, B., Geist, A., Malmbeck, R., Böhmer, V., Casensky, B., Uhlir, J., Mariani, M., Prados, P., Desreux, J.-F., Wipff, G., Ungaro, R., Hudson, M., Verboom, W., Narbutt, J.: EUROPART, FI6W-CT-2003-508 854.

2. Horwitz, E. P., Schulz, W. W.: The TRUEX Process: A Vital Tool for Disposal of U.S. Defense Nuclear Wastes. Conference on New Separation Chemistry for Radioactive Waste and Other Specific Applications, Rome, Italy, May (1990).

3. Vitart, X., Musikas, C., Pasquiou, J. Y., Hoel, P.: Séparation actinides-lanthanides à contre-courant en batterie de mélangeursdécanteurs. J. Less. Common Met. 122, 275 (1986).

4. Hill, C., Guillaneux, D., Berthon, L., Madic, C.: SANEX-BTP process development studies. J. Nucl. Sci. Technol. 3(Suppl.), 309 (2002).

5. Hudson, M. J., Foreman, M. R. S. J., Hill, C., Huet, N., Madic, C.: Solv. Extraction Ion Exch. 21, 637 (2003).

6. Pribylova, G. A., Chmutova, M. K., Smirnov, I. V., Shadrin, A. Y., Myasoedov, B. F.: Extraction of Fe(III) from nitric acid solutions with carbamoylmethylphosphine oxides and separation of Fe(III) from An(III). Radiochemistry 38, 139 (1996). 